\title{
Natural Polyphenols Enhance Stability of Crosslinked UHMWPE for Joint Implants
}

\author{
Jie Shen MEng, Guorong Gao MEng, \\ Xincai Liu PhD, Jun Fu PhD
}

Published online: 9 August 2014

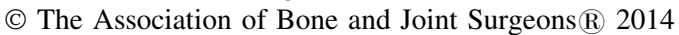

\begin{abstract}
Background Radiation-crosslinked UHMWPE has been used for joint implants since the 1990s. Postirradiation remelting enhances oxidative stability, but with some loss in strength and toughness. Vitamin E-stabilized crosslinked UHMWPE has shown improved strength and stability as compared with irradiated and remelted UHMWPE. With more active phenolic hydroxyl groups, natural polyphenols are widely used in the food and pharmaceutical industries
\end{abstract}

One or more of the authors have received funding from the Hundred Talents Program of the Chinese Academy of Sciences (JF), the Natural Science Foundation of China (Numbers 21004074 and $212101064[\mathrm{JF}]$ ), the Zhejiang Provincial Natural Science Foundation of China (Number LR13B040001 [JF]), and the Scientific Research Foundation for the Returned Overseas Chinese Scholars, State Education Ministry (JF).

All ICMJE Conflict of Interest Forms for authors and Clinical Orthopaedics and Related Research ${ }^{\mathbb{R}}$ editors and board members are on file with the publication and can be viewed on request.

Clinical Orthopaedics and Related Research ${ }^{\circledR}$ neither advocates nor endorses the use of any treatment, drug, or device. Readers are encouraged to always seek additional information, including FDA-approval status, of any drug or device prior to clinical use. This work was performed at Ningbo Institute of Materials Technology and Engineering, Chinese Academy of Sciences (Ningbo, China), and Ningbo University (Ningbo, China).

J. Shen, G. Gao, J. Fu ( $ه)$

Ningbo Key Laboratory of Polymer Materials, Polymers and Composites Division, Ningbo Institute of Materials Technology and Engineering, Chinese Academy of Sciences, 1219

Zhongguan West Road, Zhenhai District, Ningbo 315201, People's Republic of China

e-mail: fujun@nimte.ac.cn

J. Shen, X. Liu

Faculty of Materials Science and Chemical Engineering, Ningbo University, Ningbo, Zhejiang Province,

People's Republic of China as potent stabilizers and could be useful for oxidative stability in crosslinked UHMWPE.

Questions/purposes We asked whether UHMWPE blended with polyphenols would (1) show higher oxidation resistance after radiation crosslinking; (2) preserve the mechanical properties of UHMWPE after accelerated aging; and (3) alter the wear resistance of radiation-crosslinked UHMWPE.

Methods The polyphenols, gallic acid and dodecyl gallate, were blended with medical-grade UHMWPE followed by consolidation and electron beam irradiation at $100 \mathrm{kGy}$. Radiation-crosslinked virgin and vitamin E-blended UHMWPEs were used as reference materials. The UHMWPEs were aged at $120{ }^{\circ} \mathrm{C}$ in air with oxidation levels analyzed by infrared spectroscopy. Tensile $(\mathrm{n}=5$ per group) and impact ( $\mathrm{n}=3$ per group) properties before and after aging as per ASTM F2003 were evaluated. The wear rates were examined by pin-on-disc testing $(\mathrm{n}=3$ per group). The data were reported as mean \pm SDs. Statistical analysis was performed by using Student's t-test for a two-tailed distribution with unequal variance for tensile and impact data obtained with $\mathrm{n} \geq 3$. A significant difference is defined with $\mathrm{p}<0.05$.

Results The oxidation induction time of $100 \mathrm{kGy}$ UHMWPE was prolonged to 144 hours with $0.05 \mathrm{wt} \%$ dodecyl gallate and 192 hours with $0.05 \mathrm{wt} \%$ gallic acid compared with 48 hours for $0.05 \mathrm{wt} \%$ vitamin E-blended UHMWPE. Accelerated aging of these polyphenol-blended UHMWPEs resulted in ultimate tensile strength of $50.4 \pm 1.4 \mathrm{MPa}$ and impact strength of $53 \pm 5 \mathrm{~kJ} / \mathrm{m}^{2}$ for $100 \mathrm{kGy}$-irradiated UHMWPE with $0.05 \mathrm{wt} \%$ dodecyl gallate, for example, in comparison to $51.2 \pm 0.7 \mathrm{MPa}$ $(\mathrm{p}=0.75)$ and $58 \pm 5 \mathrm{~kJ} / \mathrm{m}^{2}(\mathrm{p}=0.29)$ before aging. The pin-on-disc wear rates of $100 \mathrm{kGy}$-irradiated UHMWPE with $0.05 \mathrm{wt} \%$ dodecyl gallate and $0.05 \mathrm{wt} \%$ gallic acid 
were $2.29 \pm 0.31$ and $1.65 \pm 0.32 \mathrm{mg} /$ million cycles, comparable to $1.68 \pm 0.25$ and $2.05 \pm 0.22 \mathrm{mg} / \mathrm{million}$ cycles for $100 \mathrm{kGy}$-irradiated virgin and $0.05 \mathrm{wt} \%$ vitamin E-blended UHMWPE.

Conclusions Based on the sample numbers tested in this study, polyphenols appear to effectively enhance the oxidation stability without altering the mechanical properties or pin-on-disc wear rate of radiation-crosslinked UHMWPE.

Clinical Relevance Crosslinked UHMWPE with natural polyphenols with improved oxidative stability and low wear may find clinical application in joint implants.

\section{Introduction}

Currently, more than 600,000 total joint arthroplasties are performed each year in the United States. This number is estimated to exceed 4 million per year by 2030 [20]. More than $70 \%$ of total joint implants consist of a metal or ceramic component articulating against a UHMWPE component $[21,26]$. The long-term oxidation of historical UHMWPE components sterilized in the presence of oxygen is a cause of fracture[4] and wear [46] that can lead to osteolysis, aseptic loosening, and instability, which are common reasons for revision total joint arthroplasty [26, 39]. Radiation-crosslinked UHMWPE has been used clinically for joint implants since the 1990s [21]. The highly crosslinked materials lead to $70 \%$ to $90 \%$ reduction in wear rates according to 10-year followup studies [25]. Postirradiation thermal treatments $[8,24,30]$, ie, annealing below the peak melting point and remelting above the melting point, have been used to reduce the levels of radicals generated during ionizing irradiation that otherwise would induce oxidation and embrittlement. Despite the clinical success of these materials for more than one decade, the decreased mechanical strength and fatigue resistance remain as concerns and may account for reports of early rim fractures of implants $[14,15]$. Moreover, in vivo oxidation of implants and in vitro oxidation of explants have recently been reported [6, 7, 28], even for remelted crosslinked UHMWPEs that show excellent oxidative stability during laboratory tests. In vivo challenges, including cyclic loading and synovial fluid lipid adsorption, have been suggested as possible mechanisms for in vivo or ex vivo oxidation of remelted UHMWPE implants [32, 34].

Stabilization of irradiated UHMWPE with antioxidants has been studied extensively in vitro and has demonstrated a promising alternative strategy to prevent UHMWPE oxidation [13, 16, 17, 45]. Vitamin E, or more specifically $\alpha$-tocopherol, has been introduced into clinical use and to date appears to be a successful antioxidant used to stabilize radiation-crosslinked UHMWPE. The stabilization mechanism involves the abstraction of a hydrogen radical from the phenolic hydroxyl group by a macroradical by irradiation $[1,5]$. No postirradiation thermal treatments are necessary in the presence of vitamin $E$; the crystal structures and thus the tensile strength and impact toughness are improved in comparison to the first-generation highly crosslinked and remelted UHMWPEs [38], which may be beneficial for joint implants. Moreover, vitamin E in trace amounts [22] has been demonstrated to be effective in preventing lipid-related oxidation according to laboratory studies [12].

Natural polyphenols as free radical scavengers have been widely used in food and pharmaceutics as potent antioxidants [3, 11]. In contrast to vitamin $\mathrm{E}$, natural polyphenols containing multiple phenolic hydroxyl groups may offer higher antioxidation capability. Consequently, we asked whether UHMWPE blended with two natural polyphenols would (1) show higher oxidation resistance after radiation crosslinking; (2) preserve the mechanical properties of UHMWPE after accelerated aging; and (3) alter the wear resistance of radiation-crosslinked UHMWPE.

\section{Materials and Methods}

\section{UHMWPE Materials}

We investigated radiation-crosslinked UHMWPE with two natural polyphenols, gallic acid and dodecyl gallate, containing three phenolic hydroxyl groups each with radiationcrosslinked virgin and vitamin E-blended UHMWPE as controls. Medical-grade UHMWPE (GUR ${ }^{\circledR}$ 1050; Ticona, Hoechst, Germany) was used for all UHMWPE materials tested. The polyphenol-blended UHMWPE materials were prepared as follows. First, gallic acid and dodecyl gallate were dissolved in acetone and the solutions were blended with UHMWPE powder with $1 \mathrm{wt} \%$ polyphenol with homogeneous polyphenol distribution. The blended powders were dried at $60{ }^{\circ} \mathrm{C}$ in a vacuum oven for 1 week and diluted with virgin UHMWPE powders to achieve final concentrations of 0.05 and $0.1 \mathrm{wt} \%$, because these values have been documented in the literature $[5,17]$ and are of clinical relevance.

Consolidation was performed through slab compression. To avoid UHMWPE oxidation during the consolidation process, the blended powders were preheated in a stainless steel mold at $200{ }^{\circ} \mathrm{C}$ in a vacuum oven until the polyphenol-blended UHMWPE powders completely melted followed by consolidation at $190{ }^{\circ} \mathrm{C}$ and $10 \mathrm{MPa}$ for 30 minutes by using a hydraulic press. After cooling down to room temperature, polyphenol-blended UHMWPE blocks with $10 \mathrm{~cm}$ diameter and approximately $1.5 \mathrm{~cm}$ height were obtained. The consolidated blocks were 
vacuum-packaged and irradiated with a $10-\mathrm{MeV}$ electron beam (Huaneng Electron Accelerator Co, Shaoxing, China) at $25 \mathrm{kGy}$ per pass at room temperature to a total dose of $100 \mathrm{kGy}$. The temperature of the samples after each irradiation run was no higher than $50{ }^{\circ} \mathrm{C}$. Radiationcrosslinked virgin and vitamin E-blended blocks were prepared in our laboratory following the procedure described previously without using polyphenols and used as reference.

\section{Oxidation Level}

Two accelerated aging protocols were used, one to determine oxidation level and the other to determine the mechanical properties of the UHMWPE. In the first method, thin slices of UHMWPE (one slice for each material) were aged at $120{ }^{\circ} \mathrm{C}$ to distinguish the antioxidation potency in a relatively short time scale, as reported in the literature [16]. Thin slices of the UHMWPE were microtomed to a thickness of $100 \mu \mathrm{m}$ and subjected to accelerated aging in a ventilated oven at $120{ }^{\circ} \mathrm{C}$ until the samples became too brittle to handle. This aging was replicated for three times for all the slices to verify the reproducibility of the results. The oxidation levels of UHMWPEs were tracked and examined through Fourier transform infrared (FTIR) spectroscopic analysis. FTIR spectra of the oxidized samples after hexane extraction were collected in transmission mode from 4000 to $400 \mathrm{~cm}^{-1}$ with $4 \mathrm{~cm}^{-1}$ resolution and 32 scans each using a Cary 640 spectrometer (Agilent Technologies Australia, Mulgrave, Australia). The absorbance at $1718 \mathrm{~cm}^{-1}$ (carbonyl groups) was used to evaluate the oxidation level of UHMWPE. The absorbance at $2018 \mathrm{~cm}^{-1}\left(\mathrm{CH}_{2}\right.$ twisting), which has been shown to remain relatively unaffected by the changes in the polymer structure induced by thermal, high-energy radiation or mechanical treatments, was used as the internal reference for the normalization of all spectra to an absorbance of 0.05 for a slice thickness of approximately $100 \mu \mathrm{m}[16,40]$. The base of this peak was zeroed at $2000 \mathrm{~cm}^{-1}$. The FTIR spectra of aged samples were subtracted from those of unaged counterparts to reveal variations between the unaged and aged conditions. We determined oxidation induction time for the UHMWPEs, which was defined as the time taken for the materials to reach an oxidation level of 0.15 . For this purpose, the oxidation level was defined as the ratio of band area at 1680 to $1820 \mathrm{~cm}^{-1}$ (carbonyl stretching) over that at 1370 to $1390 \mathrm{~cm}^{-1}$ (polyethylene skeleton).

\section{Tensile and Impact Tests}

In the second accelerated aging protocol, UHMWPE blocks were aged at $70{ }^{\circ} \mathrm{C}$ in 5 atm $\mathrm{O}_{2}$ for 2 weeks as per
ASTM F2003 [41]. The effect of this aging process on the mechanical properties of the UHMWPE was investigated by tensile and impact tests before and after aging for 100$\mathrm{kGy}$-irradiated UHMWPE ( $\mathrm{n}=5$ per group). The irradiation dose of $100 \mathrm{kGy}$ is close to that applied for some of the manufactured first-generation highly crosslinked UHMWPEs, which have been in clinical use and have shown a $70 \%$ to $90 \%$ reduction in annual implant wear [25].

For uniaxial tensile tests, dumbbell-like Type V tensile samples (with $63.5 \mathrm{~mm}$ length, $3.18 \mathrm{~mm}$ width, and $7.62 \mathrm{~mm}$ gauge length; $\mathrm{n}=5$ per group) were stamped from 3.2-mm-thick UHMWPE blocks according to ASTM D638 [44]. The samples were tested on an Instron 5567 frame (Instron Inc, Norwood, MA, USA) at a crosshead speed of $10 \mathrm{~mm} /$ minute. The load and crosshead displacement were recorded and used to calculate the ultimate tensile strength and elongation at break.

For Izod impact tests, UHMWPE bars $63.5 \mathrm{~mm}$ long, $12.7 \mathrm{~mm}$ wide, and $6.35 \mathrm{~mm}$ thick ( $\mathrm{n}=3$ per group) were machined and double-notched with a sharp blade to a depth of $4.57 \pm 0.08 \mathrm{~mm}$ according to ASTM F648 [42]. Izod impact tests were conducted by using a XJ-50Z tester (Chengde Dahua Inc, Chengde, China). The absorbed energy of the hammer (in kilojoules per square meter) was recorded as the impact strength.

\section{Wear Tests}

We also examined the effect of polyphenol chemistry and concentration on the wear rate of irradiated UHMWPE with $100 \mathrm{kGy}$. The 100-kGy irradiated and remelted virgin UHMWPE was used a control. For this purpose, pin-ondisc (POD) tests were conducted, as recommended by ASTM G99-05 [43].

UHMWPE pins of $9 \mathrm{~mm}$ diameter and $13 \mathrm{~mm}$ length ( $n=3$ per group) were machined out of the blocks and bidirectionally tested at $2 \mathrm{~Hz}$ against implant-grade polished CoCrMo alloy discs $\left(\mathrm{R}_{\mathrm{a}}<0.05\right)$ by using a custombuilt machine with bovine serum lubrication at a constant load of $1865 \mathrm{~N}$. The bovine serum was exchanged and the pins were weighed every day to up to 2 million cycles. The weight loss was analyzed with a linear regression method to determine the mean wear rate of the UHMWPE materials.

\section{Statistical Analysis}

In this study, small sample numbers ( $\mathrm{n}=3$ or 5 per group) were used. We conducted statistical analysis to examine the significance of the difference between groups out of the 


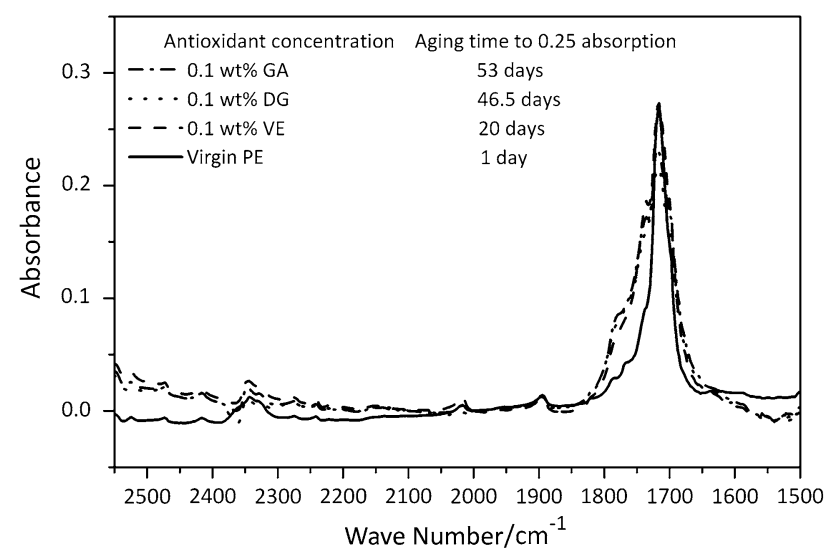

Fig. 1 FTIR spectral subtractions of UHMWPE slices with different antioxidants are summarized after aging in air at $120{ }^{\circ} \mathrm{C}$ for different times until reaching a band intensity of 0.25 at $1718 \mathrm{~cm}^{-1}$. $\mathrm{VE}=$ vitamin $\mathrm{E} ; \mathrm{DG}=$ dodecyl gallate; $\mathrm{GA}=$ gallic acid.

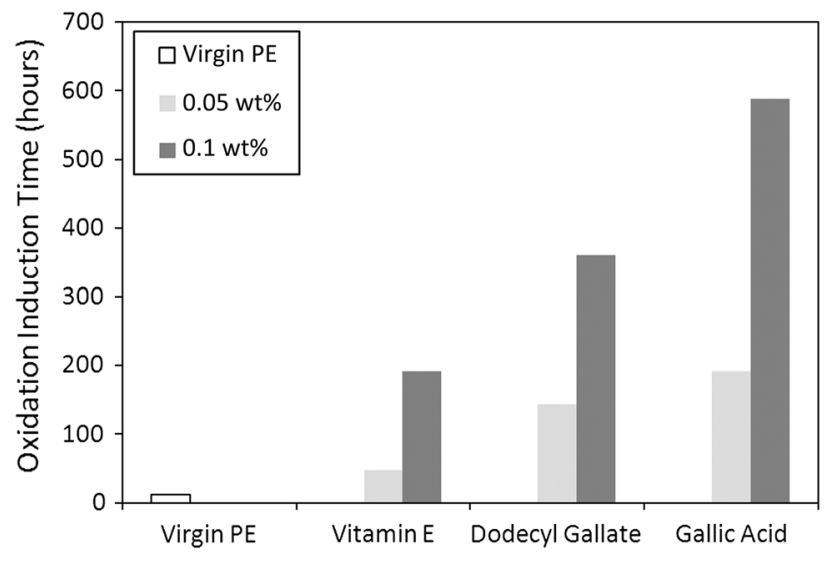

Fig. 2 Graph shows the oxidative induction time (when the absorbance at $1718 \mathrm{~cm}^{-1}$ increased to 0.15 ) of $100-\mathrm{kGy}$-irradiated UHMWPE aged in air at $120^{\circ} \mathrm{C}$. VE $=$ vitamin $\mathrm{E} ; \mathrm{DG}=$ dodecyl gallate; $\mathrm{GA}=$ gallic acid.

limited numbers available. The groups in comparison were tested by using a Student's t-test method for a two-tailed distribution with unequal variance. The threshold for a significant difference is defined at $\mathrm{p}<0.05$. The exact $\mathrm{p}$ values are shown unless they are $<0.001$.

\section{Results}

We compared the aging times needed for the UHMWPEs at $120{ }^{\circ} \mathrm{C}$ to reach a band absorbance of 0.25 at $1718 \mathrm{~cm}^{-1}$. It took 53 days for the 100-kGy-irradiated $0.1 \mathrm{wt} \%$ gallic acidblended UHMWPE compared with 46.5 days for 100-kGyirradiated $0.1 \mathrm{wt} \%$ dodecyl gallate-blended UHMWPE, 20 days for $100-\mathrm{kGy}$-irradiated $0.1 \mathrm{wt} \%$ vitamin E-blended UHMWPE, and 1 day for irradiated virgin UHMWPE (Fig. 1). The oxidation induction times of 100-kGy-irradiated $0.05 \mathrm{wt} \%$ dodecyl gallate-blended and gallic acid-blended
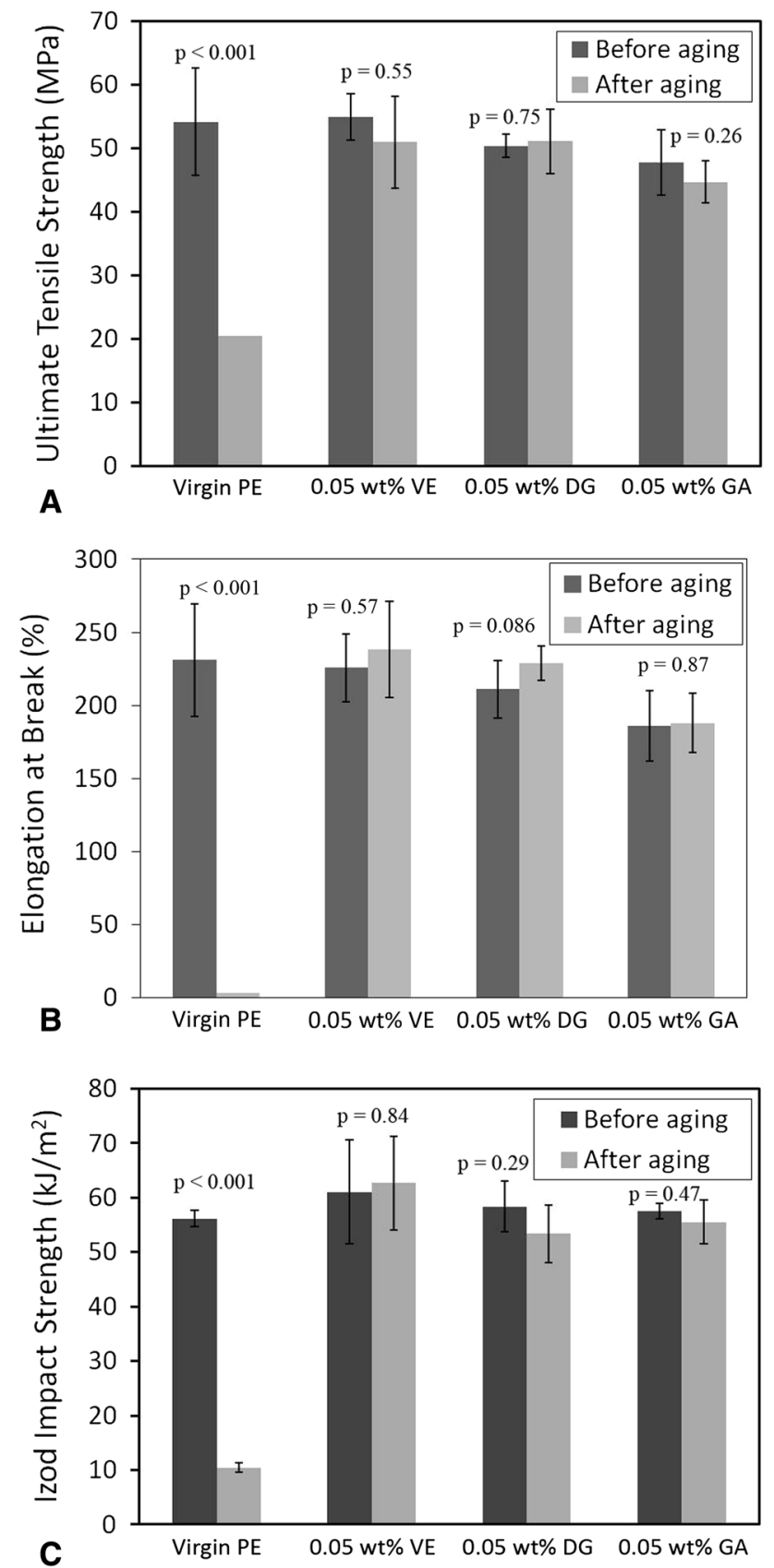

Fig. 3A-C Graphs show the mechanical properties, (A) ultimate tensile strength, $(\mathbf{B})$ elongation at break $(\mathrm{n}=5$ per group), and $(\mathbf{C})$ double-notched Izod impact strength ( $\mathrm{n}=3$ per group) of the 100kGy-irradiated UHMWPE groups with $0.05 \mathrm{wt} \%$ antioxidants before and after accelerated aging according to ASTM F2003. VE = vitamin $\mathrm{E} ; \mathrm{DG}=$ dodecyl gallate; $\mathrm{GA}=$ gallic acid.

UHMWPEs were 144 and 192 hours, respectively, which were longer than the 48 hours for $0.05 \mathrm{wt} \%$ 100-kGy-irradiated vitamin E-blended UHMWPE (Fig. 2). With $0.1 \mathrm{wt} \%$ antioxidants, the oxidative induction time was further increased to 360, 588, and 192 hours for dodecyl gallate, gallic acid, and vitamin $\mathrm{E}$, respectively. All these values were much longer than for virgin UHMWPE (approximately 12 hours). 


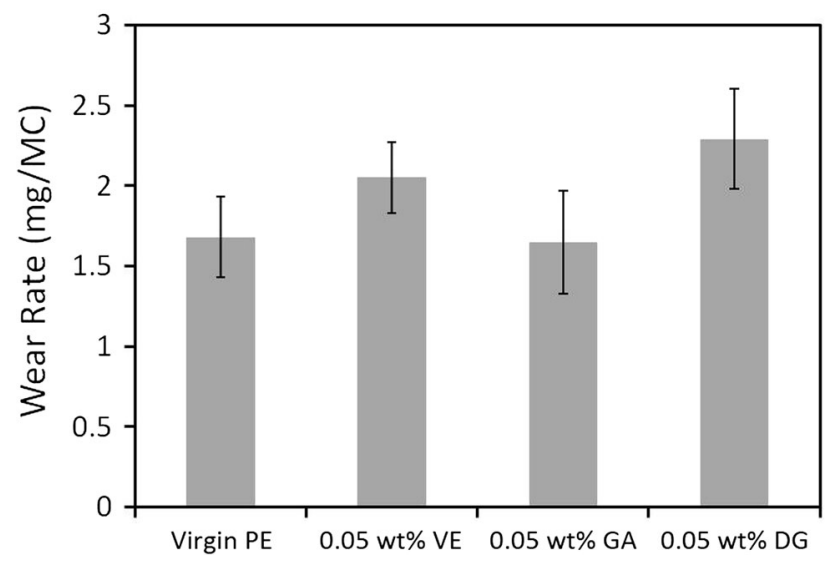

Fig. 4 Graph shows the wear rates of 100-kGy irradiated UHMWPE materials with $0.05 \mathrm{wt} \%$ antioxidants $(\mathrm{n}=3$ per group). $\mathrm{VE}=$ vitamin $\mathrm{E} ; \mathrm{DG}=$ dodecyl gallate; $\mathrm{GA}=$ gallic acid; $\mathrm{MC}=$ million cycles.

The mechanical properties of the 100-kGy-irradiated UHMWPE with antioxidants were preserved after accelerated aging according to ASTM F2003 (Fig. 3). For 100kGy-irradiated virgin UHMWPE, aging at $70{ }^{\circ} \mathrm{C}$ in $5 \mathrm{~atm}$ $\mathrm{O}_{2}$ for 2 weeks decreased its tensile strength, elongation, and Izod impact strength from $55.5 \pm 7.9 \mathrm{MPa}$, $231 \% \pm 38 \%$, and $56 \pm 2 \mathrm{~kJ} / \mathrm{m}^{2}$ before aging to less than $20 \mathrm{MPa}, 2 \%(\mathrm{n}=1$, only one specimen survived), and $10 \pm 1 \mathrm{~kJ} / \mathrm{m}^{2}$ after aging $(\mathrm{p}<0.001)$, respectively. In contrast, with the numbers available, the ultimate tensile strength values before and after aging are $50.3 \pm 1.8 \mathrm{MPa}$ and $51.0 \pm 5.1 \mathrm{MPa}$ with $0.05 \mathrm{wt} \%$ dodecyl gallate (DG, $\mathrm{p}=0.75), \quad 47.8 \pm 5.1 \mathrm{MPa}$ and $44.7 \pm 3.3 \mathrm{MPa}$ with $0.05 \mathrm{wt} \%$ gallic acid $(\mathrm{GA}, \mathrm{p}=0.26)$, and $54.9 \pm 3.6 \mathrm{MPa}$ and $50.9 \pm 7.2 \mathrm{MPa}$ with $0.05 \mathrm{wt} \%$ vitamin $\mathrm{E}$ (VE, $\mathrm{p}=0.36$ ). The elongation at break values before and after aging are $211 \pm 19.6 \%$ and $229 \pm 11.8 \%$ with $0.05 \mathrm{wt} \%$ DG $(\mathrm{p}=0.086), 186 \pm 24.2 \%$ and $188 \pm 20.3 \%$ with $0.05 \mathrm{wt} \%$ GA $(\mathrm{p}=0.87)$, and $226 \pm 23.4 \%$ and $238 \pm 32.9 \%$ with 0.05 wt $\%$ VE $(p=0.57)$. The Izod impact strength values before and after aging are $58.3 \pm 4.6 \mathrm{MPa}$ and $53.4 \pm 5.3 \mathrm{MPa}$ with $0.05 \mathrm{wt} \%$ DG $(\mathrm{p}=0.29), \quad 57.4 \pm 1.4 \mathrm{MPa}$ and $55.5 \pm 4.0 \mathrm{MPa}$ with $0.05 \mathrm{wt} \%$ GA $(\mathrm{p}=0.47)$, and $61.1 \pm 9.5 \mathrm{MPa}$ and $62.6 \pm 8.6 \mathrm{MPa}$ with $0.05 \mathrm{wt} \% \mathrm{VE}(\mathrm{p}=0.84)$. On the other hand, these values are not different from those for virgin UHMWPE before aging with the numbers available.

The 100-kGy-irradiated polyphenol-blended UHMWPE showed low wear rates with POD tests (Fig. 4). With the numbers available, the wear rate of $100-\mathrm{kGy}$-irradiated $0.05 \mathrm{wt} \%$ gallic acid-blended UHMWPE $(1.65 \pm 0.32 \mathrm{mg} /$ million cycles) was comparable to that of $100-\mathrm{kGy}$-irradiated and remelted virgin UHMWPE $(1.68 \pm 0.25 \mathrm{mg} /$ million cycles) and 100-kGy-irradiated $0.05 \mathrm{wt} \%$ vitamin E-blended UHMWPE $(2.05 \pm 0.22 \mathrm{mg} /$ million cycles $)$.
Note that the wear rate of unirradiated virgin UHMWPE was $12.38 \pm 2.28 \mathrm{mg} /$ million cycles as tested in our laboratory.

\section{Discussion}

Midterm clinical followup studies on highly crosslinked UHMWPE components have found $70 \%$ to $90 \%$ reduction in wear rates [25]. The decreased mechanical strength and fatigue resistance remain as concerns [14, 15]. Alternatively, stabilization of irradiated UHMWPE with vitamin E has improved strength and toughness [35-38]. Natural polyphenols have been used in food and pharmaceutics as potent antioxidants $[3,11]$. Herein, the use of gallic acid and dodecyl gallate appeared to effectively improve the oxidative stability of radiation-crosslinked UHMWPE. The tensile and impact properties of these polyphenol-stabilized irradiated UHMWPE were preserved after accelerated aging. Moreover, these stabilized materials qualitatively showed low wear rates comparable to those of highly crosslinked and remelted UHMWPE and vitamin E-stabilized crosslinked UHMWPE.

We acknowledge that there are limitations to our study. First, we accelerated the oxidative reactions in irradiated UHMWPE through a procedure that involves temperatures much higher than human body temperature and is incapable of mimicking the in vivo environment of an UHMWPE implant in the human body. Thus, we did not attempt to predict the in vivo performance of polyphenol-blended UHMWPE. Rather, we sought to compare the antioxidation capability of polyphenols with vitamin $\mathrm{E}$ by oxidizing the antioxidant-containing UHMWPEs under the same accelerated aging conditions. Second, the outcome of oxidative induction time was conducted through single-sample groups. Replicate experiments (data not shown) presented results with strong consistence with those reported in Fig. 2. Third, the tensile and impact results are based on tests with small sample size. According to the mean and SD values as well as $\mathrm{p}$ values, these data showed narrow distribution with the numbers available, which could be regarded as representative, although larger sample sizes may provide stronger confidence.

Oxidation of UHMWPE articular implants initiated by radicals generated by irradiation could reduce the mechanical properties by $20 \%$ to $90 \%$, depending on the oxidation level $[9,23]$, which was also demonstrated by our data obtained for the unstabilized UHMWPE. The use of antioxidants to stabilize the radicals in irradiated UHMWPE has been successful in both experimental studies and clinical applications. Vitamin $\mathrm{E}$ is a potent antioxidant to stabilize the radicals and improves the oxidative stability of radiation-crosslinked UHMWPE $[2,22$, 
27]. In our study, the time to reach a specific oxidation level was qualitatively much longer for polyphenol-blended UHMWPE than virgin UHMWPE (Fig. 1), suggesting the polyphenols were effective in stabilizing the macroradicals to delay the postirradiation oxidation of UHMWPE as vitamin E does [36]. Moreover, the oxidative induction times of gallic acid-blended and dodecyl gallateblended UHMWPEs were qualitatively longer than those of vitamin E-blended UHMWPE at antioxidant concentrations of 0.05 and $0.1 \mathrm{wt} \%$ (Fig. 2), suggesting a higher antioxidation potency of polyphenols than vitamin $\mathrm{E}$.

The tensile and impact properties were retained for the polyphenol-stabilized irradiated UHMWPE after accelerated aging according to ASTM F2003. In comparison to the dramatic drop in the strength and toughness of irradiated virgin UHMWPE after aging, the ultimate tensile strength, elongation at break, and impact strength values of irradiated polyphenol-blended UHMWPE showed no differences after accelerated aging versus before aging (Fig. 3). Moreover, the presence of $0.05 \mathrm{wt} \%$ polyphenols did not adversely affect the strength and toughness of UHMWPE. These mechanical properties may be improved in comparison to the first-generation highly crosslinked and remelted UHMWPEs and hopefully would not decrease as a result of the loss of oxidative stability.

The wear rate of crosslinked UHMWPE is also an important parameter influencing joint implant survivorship. Previous studies have demonstrated that radiation crosslinking significantly reduces UHMWPE wear [18, 29, 31, 33]. Moreover, clinical studies of highly crosslinked UHMWPE joint arthroplasty have confirmed these findings with approximately $30 \%$ to $80 \%$ reduction in wear compared with noncrosslinked conventional UHMWPE at 3 to 5 years $[10,19]$. In our study, the use of gallic acid and dodecyl gallate with $0.05 \mathrm{wt} \%$ and $0.1 \mathrm{wt} \%$ concentrations did not reduce the crosslink density of the materials [13]. With the introduction of $0.05 \mathrm{wt} \%$ dodecyl gallate and gallic acid, the wear resistance of UHMWPE materials was not altered and comparable to that of $0.05 \mathrm{wt} \%$ vitamin $\mathrm{E}$ blended UHMWPE receiving the same radiation dose (Fig. 4). Moreover, high-dose irradiation did not detrimentally decrease the stability of gallic acid and dodecyl gallate, which, with the numbers available, exhibit an improved oxidative stability compared with vitamin $\mathrm{E}$ at the same concentration and irradiation dose (Fig. 2).

This study suggests that polyphenol-blended UHMWPEs exhibit improvements in oxidation resistance, as measured by oxidation induction time, in comparison with vitamin Eblended materials while preserving mechanical properties after accelerated aging based on the sample numbers available. The addition of polyphenols to UHMWPE did not alter the low POD wear rates after irradiation. Such strong antioxidation potency of radiation-crosslinked
UHMWPE containing natural polyphenols, together with low wear, may find potential clinical applications for orthopaedic implants. Further research is needed to evaluate the oxidative stability of polyphenol-blended UHMWPE in the presence of synovial fluid lipids, which may offer useful clues to the possible performance of these materials in vivo.

Acknowledgments We thank Professor Luigi Costa $\mathrm{PhD}$, for fruitful discussions and $\mathrm{Mr}$ Ronghui Chen and his team for assistance in electron beam irradiation.

\section{References}

1. Bracco P, Brunella V, Zanetti M, Luda MP, Costa L. Stabilisation of ultra-high molecular weight polyethylene with vitamin $\mathrm{E}$. Polym Degrad Stab. 2007;92:2155-2162.

2. Bracco P, Oral E. Vitamin E-stabilized uhmwpe for total joint implants: a review. Clin Orthop Relat Res. 2011;469:2286-2293.

3. Cirillo G, Kraemer K, Fuessel S, Puoci F, Curcio M, Spizzirri UG, Altimari I, Iemma F. Biological activity of a gallic acidgelatin conjugate. Biomacromolecules. 2010;11:3309-3315.

4. Cole J, Lemons J, Eberhardt A. Gamma irradiation alters fatiguecrack behavior and fracture toughness in $1900 \mathrm{H}$ and GUR 1050 UHMWPE. J Biomed Mater Res. 2002;63:559-566.

5. Costa L, Carpentieri I, Bracco P. Post electron-beam irradiation oxidation of orthopedic Ultra-High Molecular Weight Polyethylene (UHMWPE) stabilized with vitamin E. Polym Degrad Stab. 2009;94:1542-1547.

6. Currier BH, Van Citters DW, Currier JH, Carlson EM, Tibbo ME, Collier JP. In vivo oxidation in retrieved highly crosslinked tibial inserts. J Biomed Mater Res Part B Appl Biomat. 2013;101:441-448.

7. Currier BH, Van Citters DW, Currier JH, Collier JP. In vivo oxidation in remelted highly cross-linked retrievals. J Bone Joint Surg Am. 2010;92:2409-2418.

8. Dumbleton J, D'Antonio J, Manley M, Capello W, Wang A. The basis for a second-generation highly cross-linked UHMWPE. Clin Orthop Relat Res. 2006;453:265-271.

9. Edidin AA, Jewett CW, Kalinowski A, Kwarteng K, Kurtz SM. Degradation of mechanical behavior in UHMWPE after natural and accelerated aging. Biomaterials. 2000;21:1451-1460.

10. Engh CA Jr, Stepniewski AS, Ginn SD, Beykirch SE, SychterzTerefenko CJ, Hopper RH Jr, Engh CA. A randomized prospective evaluation of outcomes after total hip arthroplasty using cross-linked marathon and non-cross-linked Enduron polyethylene liners. J Arthroplasty. 2006;21:17-25.

11. Fiuza SM, Gomes C, Teixeira LJ, Girão da Cruz MT, Cordeiro MNDS, Milhazes N, Borges F, Marques MPM. Phenolic acid derivatives with potential anticancer properties-a structureactivity relationship study. Part 1: Methyl, propyl and octyl esters of caffeic and gallic acids. Bioorg Med Chem. 2004;12:3581-3589.

12. Fu J, Doshi BN, Oral E, Muratoglu OK. High temperature melted, radiation cross-linked, vitamin $\mathrm{E}$ stabilized oxidation resistant UHMWPE with low wear and high impact strength. Polymer. 2013;54:199-209.

13. Fu J, Shen J, Gao G, Xu Y, Hou R, Cong Y, Cheng Y. Natural polyphenol-stabilised highly crosslinked UHMWPE with high mechanical properties and low wear for joint implants. J Mater Chem B. 2013;1:4727-4735.

14. Furmanski J, Anderson M, Bal S, Greenwald AS, Halley D, Penenberg B, Ries M, Pruitt L. Clinical fracture of cross-linked UHMWPE acetabular liners. Biomaterials. 2009;30:5572-5582. 
15. Furmanski J, Kraay MJ, Rimnac CM. Crack initiation in retrieved cross-linked highly cross-linked ultrahigh-molecular-weight polyethylene acetabular liners. An investigation of 9 cases. J Arthroplasty. 2011;26:796-801.

16. Gallardo LA, Carpentieri I, Laurent MP, Costa L, Wimmer MA. Europium stearate additives delay oxidation of UHMWPE for orthopaedic applications: a pilot study. Clin Orthop Relat Res. 2011;469:2294-2301.

17. Gijsman P, Smelt HJ, Schumann D. Hindered amine light stabilizers: an alternative for radiation cross-linked UHMWPE implants. Biomaterials. 2010;31:6685-6691.

18. Grobbelaar CJ, Duplessis TA, Marais F. Radiation improvement of polyethylene prostheses-preliminary-study. J Bone Joint Surg Br. 1978;60:370-374.

19. Ise K, Kawanabe K, Tamura J, Akiyama H, Goto K, Nakamura T. Clinical results of the wear performance of cross-linked polyethylene in total hip arthroplasty prospective randomized trial. J Arthroplasty. 2009;24:1216-1220.

20. Kurtz S, Ong K, Lau E, Mowat F, Halpern M. Projections of primary and revision hip and knee arthroplasty in the United States from 2005 to 2030. J Bone Joint Surg Am. 2007;89:780785.

21. Kurtz SM, ed. UHMWPE Biomaterials Handbook. New York, NY, USA: Elsevier Inc; 2009.

22. Kurtz SM, Dumbleton J, Siskey RS, Wang A, Manley M. Trace concentrations of vitamin $\mathrm{E}$ protect radiation crosslinked UHMWPE from oxidative degradation. J Biomed Mater Res Part A. 2009;90:549-563.

23. Kurtz SM, Hozack W, Marcolongo M, Turner J, Rimnac C, Edidin A. Degradation of mechanical properties of UHMWPE acetabular liners following long-term implantation. J Arthroplasty. 2003;18:68-78.

24. Kurtz SM, Manley M, Wang A, Taylor S, Dumbleton J. Comparison of the properties of annealed crosslinked (Crossfire) and conventional polyethylene as hip bearing materials. Bull Hosp $\mathrm{J} t$ Dis NY. 2002;61:17-26.

25. Kurtz SM, Medel FJ, MacDonald DW, Parvizi J, Kraay MJ, Rimnac CM. Reasons for revision of first-generation highly cross-linked polyethylenes. J Arthroplasty. 2010;25:67-74.

26. Kurtz SM, Muratoglu OK, Evans M, Edidin AA. Advances in the processing, sterilization, and crosslinking of ultra-high molecular weight polyethylene for total joint arthroplasty. Biomaterials. 1999;20:1659-1688.

27. Lerf R, Zurbrügg D, Delfosse D. Use of vitamin E to protect cross-linked UHMWPE from oxidation. Biomaterials. 2010;31:3643-3648.

28. MacDonald D, Sakona A, Ianuzzi A, Rimnac CM, Kurtz SM. Do first-generation highly crosslinked polyethylenes oxidize in vivo? Clin Orthop Relat Res. 2011;469:2278-2285.

29. McKellop H, Shen FW, Lu B, Campbell P, Salovey R. Development of an extremely wear-resistant ultra high molecular weight polyethylene for total hip replacements. J Orthop Res. 1999;17:157-167.

30. Muratoglu OK, Bragdon CR, O'Connor DO, Jasty M, Harris WH. A novel method of cross-linking ultra-high-molecular-weight polyethylene to improve wear, reduce oxidation, and retain mechanical properties. Recipient of the 1999 HAP Paul Award. J Arthroplasty. 2001;16:149-160.

31. Muratoglu OK, Bragdon CR, O'Connor DO, Jasty M, Harris WH, Gul R, McGarry F. Unified wear model for highly crosslinked ultra-high molecular weight polyethylenes (UHMWPE). Biomaterials. 1999;20:1463-1470.

32. Muratoglu OK, Wannomae KK, Rowell SL, Micheli BR, Malchau $\mathrm{H}$. Ex vivo stability loss of irradiated and melted ultra-high molecular weight polyethylene. $J$ Bone Joint Surg Am. 2010;92:2809-2816.

33. Oonishi H, Kuno M, Tsuji E, Fujisawa A. The optimum dose of gamma radiation-heavy doses to low wear polyethylene in total hip prostheses. J Mater Sci Mater Med. 1997;8:11-18.

34. Oral E, Ghali BW, Neils A, Muratoglu OK. A new mechanism of oxidation in ultrahigh molecular weight polyethylene caused by squalene absorption. J Biomed Mater Res Part B Appl Biomat. 2012;100:742-751.

35. Oral E, Ghali BW, Rowell SL, Micheli BR, Lozynsky AJ, Muratoglu OK. A surface crosslinked UHMWPE stabilized by vitamin $\mathrm{E}$ with low wear and high fatigue strength. Biomaterials. 2010;31:7051-7060.

36. Oral E, Greenbaum ES, Malhi AS, Harris WH, Muratoglu OK. Characterization of irradiated blends of alpha-tocopherol and UHMWPE. Biomaterials. 2005;26:6657-6663.

37. Oral E, Neils AL, Lyons C, Fung M, Doshi B, Muratoglu OK. Surface cross-linked UHMWPE can enable the use of larger femoral heads in total joints. J Orthop Res. 2013;31:59-66.

38. Oral E, Wannomae KK, Hawkins N, Harris WH, Muratoglu OK. Alpha-tocopherol-doped irradiated UHMWPE for high fatigue resistance and low wear. Biomaterials. 2004;25:5515-5522.

39. Paxton EW, Inacio M, Slipchenko T, Fithian DC. The Kaiser Permanente national total joint replacement registry. Permanente J. 2008;12:12-16.

40. Solti A, Hummel D, Simak P. Computer-supported infrared spectrometry of polyethylene, ethen copolymers, and amorphous poly(alkyl ethylene)s. Makromol Chem Macromol Symp. 1986;5:105-133.

41. Standard Practice for Accelerated Aging of Ultra-high Molecular Weight Polyethylene After Gamma Irradiation in Air. West Conshohocken, PA, USA: ASTM International; 2002:1-4.

42. Standard Specification for Ultra-high-molecular-weight Polyethylene Powder and Fabricated Form for Surgical Implants. West Conshohocken, PA, USA: ASTM International; 2000:1-8.

43. Standard Test Method for Wear Testing With a Pin-on-disk Apparatus. West Conshohocken, PA, USA: ASTM International; 2010:1-5.

44. Standard Test Methods for Tensile Properties of Plastics. West Conshohocken, PA, USA: ASTM International; 2003:1-15.

45. Tomita N, Kitakura T, Onmori N, Ikada Y, Aoyama E. Prevention of fatigue cracks in ultrahigh molecular weight polyethylene joint components by the addition of vitamin E. J Biomed Mater Res. 1999;48:474-478.

46. Walker P, Bell C, Abeysundera M, Simmon J, King P, Blunn G. Effect of oxidation on delamination of ultrahigh-molecularweight polyethylene tibial components. $J$ Arthroplasty. 1998;13:280-290. 